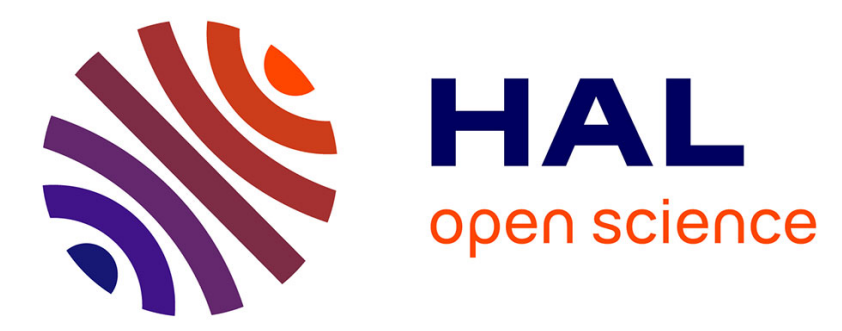

\title{
Characterizing liver capsule microstructure via in situ bulge test coupled with multiphoton imaging
}

\author{
Charles Jayyosi, Michel Coret, Karine Bruyère-Garnier
}

\section{To cite this version:}

Charles Jayyosi, Michel Coret, Karine Bruyère-Garnier. Characterizing liver capsule microstructure via in situ bulge test coupled with multiphoton imaging. Journal of the mechanical behavior of biomedical materials, 2015, 54, pp.229-243. 10.1016/j.jmbbm.2015.09.031 . hal-01546500

\author{
HAL Id: hal-01546500 \\ https://hal.science/hal-01546500
}

Submitted on 2 Oct 2017

HAL is a multi-disciplinary open access archive for the deposit and dissemination of scientific research documents, whether they are published or not. The documents may come from teaching and research institutions in France or abroad, or from public or private research centers.
L'archive ouverte pluridisciplinaire HAL, est destinée au dépôt et à la diffusion de documents scientifiques de niveau recherche, publiés ou non, émanant des établissements d'enseignement et de recherche français ou étrangers, des laboratoires publics ou privés. 


\title{
Characterizing liver capsule microstructure via in situ bulge test coupled with multiphoton imaging
}

\author{
C. Jayyosi ${ }^{a, b, c, *}$, M. Coret $^{d}$, K. Bruyère-Garnier ${ }^{a, b, c}$ \\ ${ }^{a}$ Université de Lyon, F-69622 Lyon, France \\ buniversité Claude Bernard Lyon 1, Villeurbanne, France \\ CIFSTTAR, UMR-T9406, LBMC Laboratoire de Biomécanique et Mécanique des Chocs, F69675 Bron, France

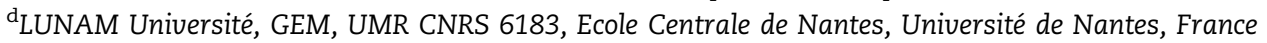

The characterization of biological tissue at the microscopic scale is the starting point of many applications in tissue engineering and especially in the development of structurally based constitutive models. In the present study, focus is made on the liver capsule, the membrane encompassing hepatic parenchyma, which takes a huge part in liver mechanical properties. An in situ bulge test experiment under a multiphoton microscope has been developed to assess the microstructure changes that arise with biaxial loading. Multiphoton microscopy allows to observe the elastin and collagen fiber networks simultaneously. Thus a description of the microstructure organization of the capsule is given, characterizing the shapes, geometry and arrangement of fibers. The orientation of fibers is calculated and orientation distribution evolution with loading is given, in the case of an equibiaxial and two non equibiaxial loadings, thanks to a circular and elliptic set up of the bulge test. The local strain fields have also been computed, by the mean of a photobleaching grid, to get an idea of what the liver capsule might experience when subjected to internal pressure. Results show that strain fields present some heterogeneity due to anisotropy. Reorientation occurs in non equibiaxial loadings and involves fibers layers from the inner to the outer surface as expected. Although there is a fiber network rearrangement to accommodate with loading in the case of equibiaxial loading, there is no significant reorientation of the main fibers direction of the different layers.
Keywords:

In situ elliptic bulge test

Photobleaching

Strain measurement

Liver capsule

Multiphoton microscopy

Fibrous connective membrane

\section{Introduction}

The characterization of soft biological tissues is of many interests since it has a lot of applications, one of them being the development of constitutive models. Structural constitutive models are of crucial importance because they can help to identify the functional parameters that are essential to tissue functions, making them valuable for tissue engineering

*Corresponding author at: IFSTTAR, UMR-T9406, LBMC Laboratoire de Biomécanique et Mécanique des Chocs, F69675 Bron, France. Tel.: +33 478656861.

E-mail address: charles.jayyosi@ifsttar.fr (C. Jayyosi). 
applications (Sacks, 2003). In order to build realistic and functional models the study of soft tissue microstructure has been an active research area. In particular, many studies aim to understand the extension and reorganization mechanisms of collagenous structures on different tissues such as tendons (Sasaki and Odajima, 1996; Screen et al., 2004), skin (Brown, 1973), connective tissue (Liao et al., 2005; Purslow et al., 1998), or arteries (Keyes et al., 2013; Rezakhaniha et al., 2012; Wang et al., 2013). Indeed, the changes in the microstructure at the fiber level can impact greatly the mechanical properties of the tissue and thus its functional purpose, affecting cell environment and behavior, leading to diseases or disorders (Engler et al., 2006; Koch et al., 2014; Pizzo et al., 2005; Robertson et al., 2012).

The identification of the relationship between microstructure and mechanical behavior needs coupling mechanical tests with microstructural observation which turns out to be challenging. Uniaxial tensile tests are often carried out and several studies present their implementation and association with a microscopic imagery technique. Therefore, uniaxial tensile tests have been used to investigate the strain and reorganization of collagen fibers in tendons (Goulam Houssen et al., 2011; Lake et al., 2010; Screen et al., 2004), but also the behavior of fetal membrane microstructure (Mauri et al., 2013, 2015) and liver capsule (Jayyosi et al., 2014). However, uniaxial tension loading might be quite far from what the tissues can experience in vivo. Röhrnbauer et al. (2013) highlighted the fact that biaxial and uniaxial loading leads to very different behaviors of the tissue and thus it is recommended to test the biological materials with a type of loading that this given tissue could be subjected to in vivo.

Biaxial testing applies a stress state that is closer from in vivo loading for some tissues, and thus experiments coupling biaxial testing and microstructure observation have been designed. Liao et al. (Liao et al., 2005) for example, applied a biaxial stretch to native bovine pericardium samples and investigated collagen fiber/molecular kinematics using a small angle light scattering and small angle X-ray scattering systems. They also highlighted the difference between the behavior of the tissue when subjected to uniaxial and biaxial loading. Keyes et al. (2011) developed a micro biaxial optomechanical device allowing to pressurized tubular samples while imaging their microstructure thanks to a multiphoton microscope. They were able to record the microstructural organization of mouse aorta under different pressured states and measured fiber orientations and composition of the arterial wall.

At the macroscopic scale, bulge test turns out to be a good solution to test biological materials since it applies a biaxial stress state, if radial stress is negligible before in-plane stress. It is usually used to test thin metallic or polymer membranes (Çakmak et al., 2014; Rivlin and Saunders, 1951; Tsakalakos and Jankowski, 1986), calculating stress by assuming a spherical deformation cap. The same process has been transposed to test many biological tissues such as skin (Tonge et al., 2013), fetal membrane (Joyce, 2009; Perrini et al., 2013), pericardium (Hildebrandt et al., 1969), sclera (Myers et al., 2010), arteries (Drexler et al., 2007), but also liver capsule (Brunon et al., 2011). For capsules encompassing pressurized organs such as liver or kidney, bulge test is particularly fitted to determine mechanical properties. Indeed, in case of impact or compression on such organs, an increased pressure arises (Sparks, 2007), submitting the surrounding membrane to a stress state very close from what bulge testing induces.

However, among the studies implementing bulge test on biological tissues, few take into account considerations about the impact of this mechanical test on the microstructure. Tonge et al. (2013) used the bulge test to assess the anisotropy in human skin. The minor axis of the ellipsoid, formed by inflation of a circular sample, is associated to the stiffest direction of the sample, which corresponds to a preferred collagen fiber orientation. Therefore they managed to get insight into the material micro organization without imaging directly the microstructure during loading.

The use of several imaging technique have been reported in order to assess tissues microstructure. Multiphoton microscopy is one of the most efficient ones for tissue composed of elastin and collagen fibers because it combines fluorescence and Second Harmonic Generation (SHG). Therefore, it allows taking advantage of the autofluorescent properties of elastin and the organization of collagen molecules that generates second harmonics (Campagnola et al., 2002; Goulam Houssen et al., 2011; Zoumi et al., 2002) to image these two different fiber networks with a single two-photon excitation microscope, while making the distinction between them (Zoumi et al., 2004, 2002). Consequently, multiphoton microscopy is very convenient compared to classic histology techniques because the sample does not need any preparation or fixation protocol before imaging, thus preventing additional tissue alteration.

The liver capsule known as Glisson's capsule is a fibrous connective membrane mainly composed of collagen and elastin fibers. It encompasses the hepatic parenchyma, to which it adheres more or less depending on the location, while remaining clearly dissociable from it for human livers. From a structural point of view, capsule makes the whole organ stiffer considering its different mechanical properties from parenchyma (Brunon et al., 2010). Since it contributes greatly to the global mechanical behavior of human liver, and it is involved in extern livers injuries, liver capsule mechanical behavior has been studied from a macroscopic point of view (Brunon et al., 2011, 2010; Dan, 1999; Hollenstein and Mazza, 2012; Valtorta and Mazza, 2005).

In a previous paper (Jayyosi et al., 2014), we already used multiphoton microscopy to assess local strain fields in liver capsule subjected to uniaxial tensile test. We took advantage of a side effect of microscopy fluorescence known as photobleaching to position markers on the fibrous structure. Following these markers during loading, we were able to measure displacement fields and the local strain field on the tissue via a finite element method interpolation. To assess local strain, other experiments have used the track of markers that are usually stained cell nuclei (Bruehlmann et al., 2004; Mauri et al., 2015; Screen and Evans, 2009).

Therefore, the aim of this study was to use the method developed in Jayyosi et al. (2014) to characterize the liver capsule microstructure, assessing the local strain field and fiber orientation, when it is subjected to a bulge test. To this end, a protocol of in situ bulge testing coupled with multiphoton microscopy imaging was developed. Consequently, 
we were able to monitor the microstructure reorganization during a mechanical loading closer to an in vivo configuration in term of applied stress. We also assessed a detailed description of liver capsule microstructure which has not been reported yet to our knowledge.

\section{Material and methods}

\subsection{Sample preparation}

Four human livers were collected through the French voluntary corpse donation to Science program from the Department of Anatomy of the University of Rockefeller (DUAR, Lyon, France). Capsule was delicately separated from the parenchyma by creating a hematoma. Even if capsule adheres to the parenchyma, it is still clearly distinct from it on human livers, and can thus be taken off on the major part of the liver. Therefore, large sections of liver capsule were dissected away from parenchyma and frozen at $-20^{\circ} \mathrm{C}$. On testing day, liver capsule was thawed at room temperature and cup into circular and elliptic shaped samples. Three shapes were chosen for the samples (Fig. 1) in order to induce an equibiaxial and non equibiaxial loading during testing. Therefore, circular samples were made (referred to as R1 i.e. ratio 1 between the two axis), as well as elliptic samples with a ratio 2 (R2) and a ratio 4 (R4) between the minor and major axis.

The shapes were actually defined by the arrangement of preholes which were made with a die cutter, forming ellipses or circles according to the case, in order to ease the passing of the clamping screws. Fig. 1 gives the dimensions of the arrangement of the clamping screws that defines the boundary conditions of the bulge test, and the associated dimensions of the samples. Table 1 gives the details of how many samples per livers were obtained and what shapes they were cut in. Samples were kept hydrated in saline solution until mounting on the inflation system where they were first positioned on the silicone joint and then clamped between the bottom cylinder and the top ring with screws (Fig. 2c). This ensemble was placed in the inflation base and the all set up was put under the multiphoton microscope (Fig. 2d and e).

a

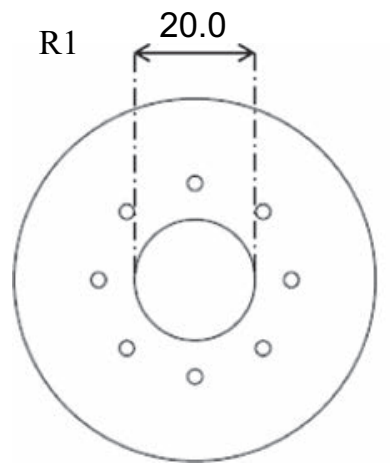

b

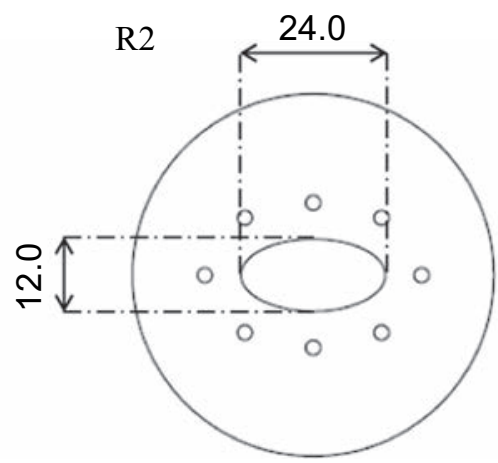

\subsection{In situ bulge test}

Inflation was made with compressed air. A tank with compressed air at 8 bars was filed and used to deliver progressive pressure increase, thanks to a first valve. A second valve was placed right after the first one to quickly shut down the compressed air flow after the sample rupture, to avoid splash of saline solution. In order to ensure the hydration of the sample throughout the all test and to allow imaging with the water objective, the sample was covered up with saline solution.

The microscope objective (NIKON, 25X, NA 1.1) was equipped with a displacement sensor that allows a measure of vertical displacement with accuracy down to $\pm 0.01 \mu \mathrm{m}$. The origin for the $\mathrm{Z}$ measurements (vertical displacements) was chosen to correspond with the state when the liver capsule is loaded to a very low pressure level $(P=0.02 \mathrm{~b})$ just to ensure a uniform curvature of the inflated sample. A reset of the pressure transducer was made before loading when the capsule was only subjected to atmospheric pressure and the weight of saline solution in the upper compartment. Consequently, all pressure measurements are relative compared to atmospheric pressure. Pressure measurements were acquired at $100 \mathrm{~Hz}$.

Loading was conducted up to failure with increments of pressure of 0.1 bar, followed by imaging after a brief pause for position and pressure stabilization. An example of the loading path is presented on Fig. 3 where red marks correspond to

Table 1 - Repartition of samples among the 4 livers tested. R1 correspond to circular shaped samples, while R2 and R4 are elliptical samples with ratio of 2 and 4 respectively between the minor and major axis. Orientation measurements were conducted on all samples whereas strain measurements were only performed on livers 3 and 4.

Liver $1 \quad$ Liver 2 Liver $3 \quad$ Liver 4

$\begin{array}{lllll}\left(0^{\prime} 89 y .0\right) & \left(0^{\prime} 86 y .0\right) & (\% 89 y .0) & (\% 97 y .0)\end{array}$

\begin{tabular}{|c|c|c|c|c|c|}
\hline \multirow[t]{3}{*}{ Number of samples } & R1 & 1 & 6 & 4 & 3 \\
\hline & R2 & 6 & 0 & 3 & 2 \\
\hline & R4 & 2 & 0 & 2 & 3 \\
\hline $\begin{array}{l}\text { Orientation } \\
\text { measurements }\end{array}$ & & $\checkmark$ & $\checkmark$ & $\checkmark$ & $\checkmark$ \\
\hline $\begin{array}{l}\text { Strain } \\
\text { measurements }\end{array}$ & & & & $\checkmark$ & $\checkmark$ \\
\hline
\end{tabular}

C

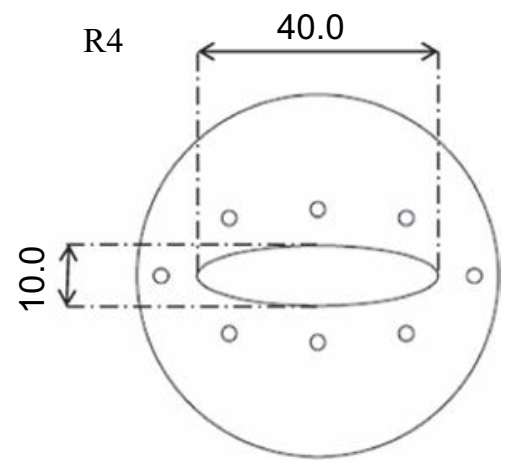

Fig. 1 - Shapes and dimension $(\mathrm{mm})$ of the relative arrangement of the clamping screws that define the boundary conditions of the different types of bulge test (a) R1, (b) R2 and (c) R4. 

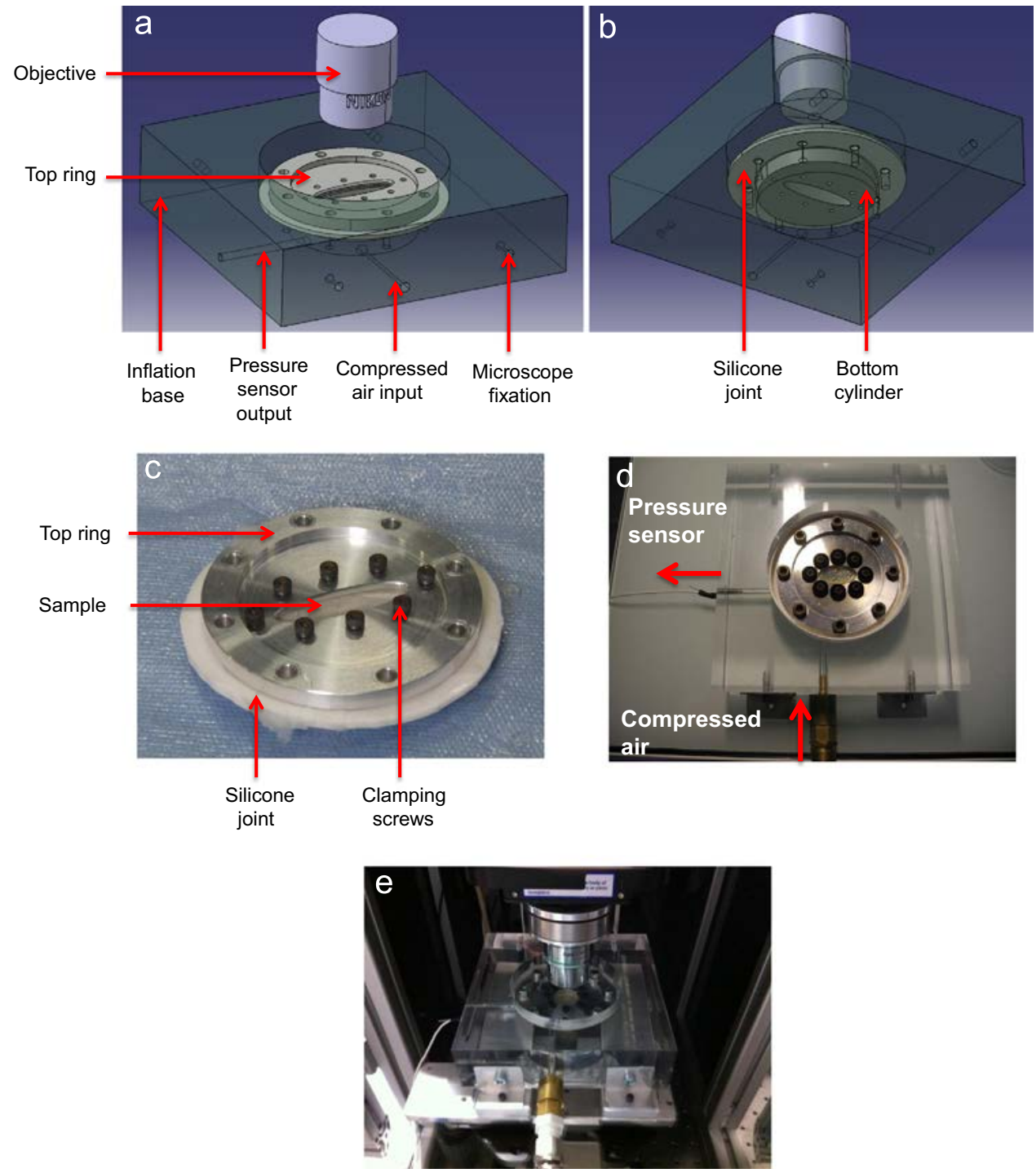

Fig. 2 - Experimental set up. (a-b) Schematic view (CATIA $®$ ) (c)Top ring with clamping screws and silicone joint for airtightness. (b) Inflation base to which is connected the pressure sensor and the compressed air inflow. (c) Set up under the two photon excitation confocal microscope at the IVTV platform (ANR-10-EQPX-06-01).

image acquisition. Position of the apex of the inflated capsule was collected via the $Z$ displacement sensor of the objective at each pressure step.

The viscoelastic behavior highlighted by the Fig. 3 has not been studied here. We were not able to investigate the changes of the microstructure during relaxation because the imaging process needed the position stabilization of the capsule. The recording process was started when the capsule position was stable enough, and consequently, the fibers orientation and strain did not change anymore (or at least not in a significant way) after the beginning of the imaging process. Thus, the measurements of orientation and strain presented in this work correspond to snapshots of the configuration after the changes induced by relaxation at the apex.

\subsection{Multiphoton imaging}

Image acquisition was performed thanks to a two photon

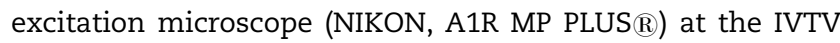

platform ("Ingénierie et Viellissement des Tissus Vivants", Engineering and Ageing of Living Tissues, ANR-10-EQPX-0601). Excitation wavelength was set to $850 \mathrm{~nm}$ and light from elastin fluorescence and collagen SHG signals was collected via two band-pass filters of $500-550 \mathrm{~nm}$ and $400-492 \mathrm{~nm}$ respectively. The total field of view was $507 \times 507 \mu \mathrm{m}^{2}$ and scan speed was set to $2 \mathrm{~s}$ per image with a resolution of $0.5 \mu \mathrm{m}$ per pixel. The whole thickness of the sample was imaged at each pressure step with a $Z$ step of $0.4 \mu \mathrm{m}$ for the objective piezo actuator. This process resulted in stacks of images of 40 to $80 \mu \mathrm{m}$ thickness approximately, depending on the sample. These setting parameters were chosen for a good compromise between image acquisition time and image quality that allows easy and satisfactory image processing analysis. A correction of the $Z$ step was computed during the post-analysis, to account for the small displacement of the liver capsule during the imaging time. Indeed, since in some cases, full stabilization was hard to achieve, the sample was sometimes still moving up or down. Therefore we corrected 


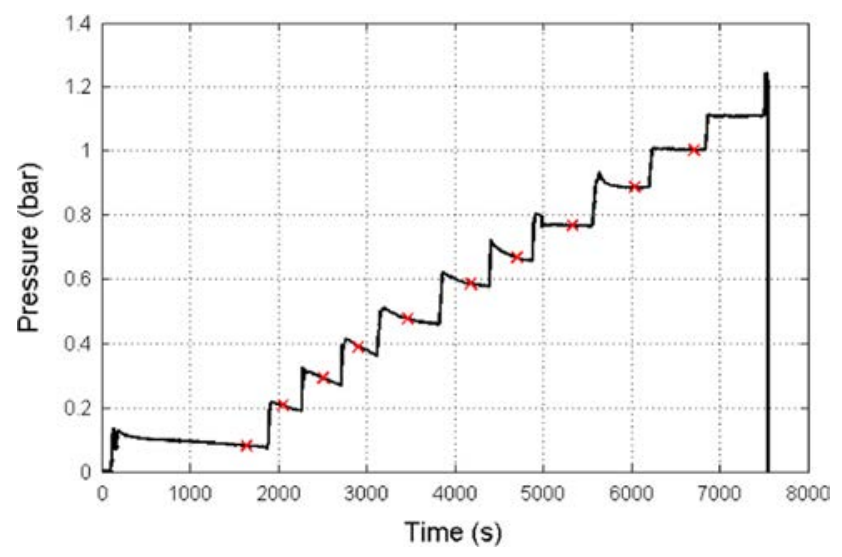

Fig. 3 - Loading path for one of the elliptical samples (R2). Loading is conducted up to failure with pressure increments of 0.1 bar. Pressure values are relative to atmospheric pressure. Red crosses correspond to the beginning of image acquisition at each step that lasted between 2-3 min. (For interpretation of the references to color in this figure legend, the reader is referred to the web version of this article.)

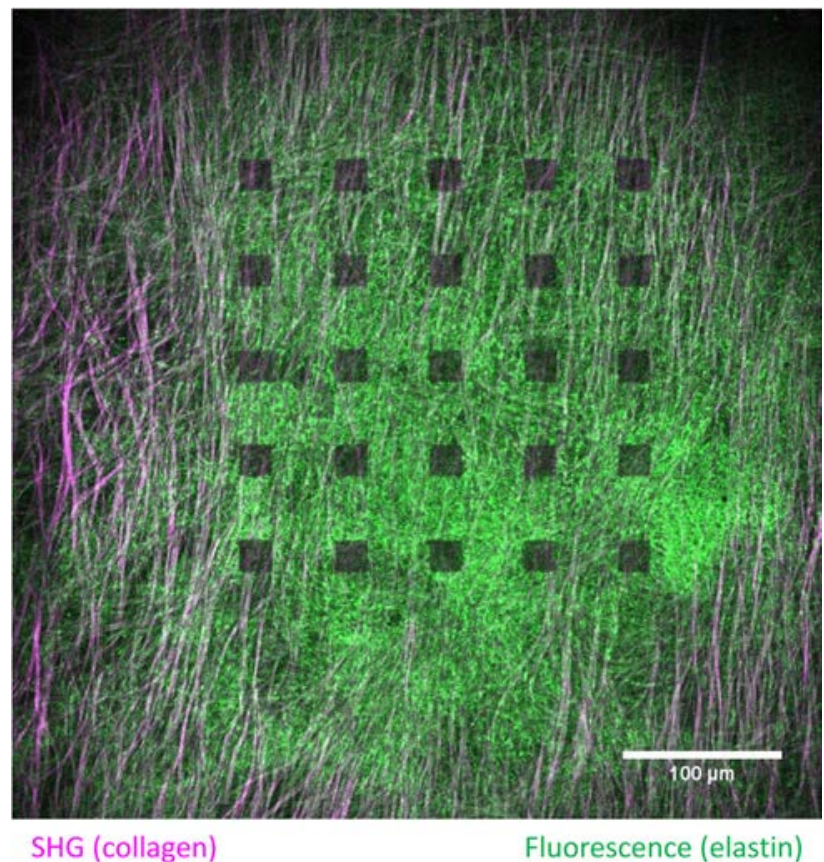

Fig. 4 - Human liver capsule observed with multiphoton microscopy at 0.1 bar. Green correspond to the fluorescence channel that shows the elastin fibers, while the Second Harmonic Generation (SHG) signal on which appear collagen fibers is shown in magenta. The photobleached grid, characterized by a local loss of fluorescence, is shown before loading. Photobleached squares are $20 \mu \mathrm{m} \times 20 \mu \mathrm{m}$ spaced with $40 \mu \mathrm{m}$. (For interpretation of the references to color in this figure legend, the reader is referred to the web version of this article.)

the initial $\mathrm{Z}$ step of $0.4 \mu \mathrm{m}$ by dividing the actual thickness of the capsule, measured before imaging, by the number of images taken. Post-analysis revealed a $Z$ step in the range of $0.35-0.5 \mu \mathrm{m}$.

After the first increment of pressure (i.e. for a pressure of $0.1 b$ ), the region of interest (ROI) was positioned at the apex of the inflated liver capsule. It was easily located, as the highest detectable signal on the sample. Then a photobleaching grid was made following the process described in Jayyosi et al. (2014). Briefly, a grid of photobleached squares was made by increasing the laser power on a specifically localized area, thus removing the fluorescence locally while conserving the SHG signal. In the ROI, a selection of a regular grid of $5 \times 5$ was made with $20 \mu \mathrm{m}$ wide squares spaced apart from $40 \mu \mathrm{m}$. Then, on that selection, laser power was set to $50 \%$ of total power source (while it is only $3 \%$ for regular imaging), for $4 \mathrm{~s}$, three times in a row. The resulting photobleaching grid is shown on Fig. 4. The total fluence (energy per unit area) for this process was $90 \mathrm{~J} \mathrm{~mm}^{-2}$, which was shown to be a good compromise to get highly contrasted photobleached squares while preventing tissue damage (Jayyosi et al., 2014). Eventually, these photobleached squares were imaged during the 

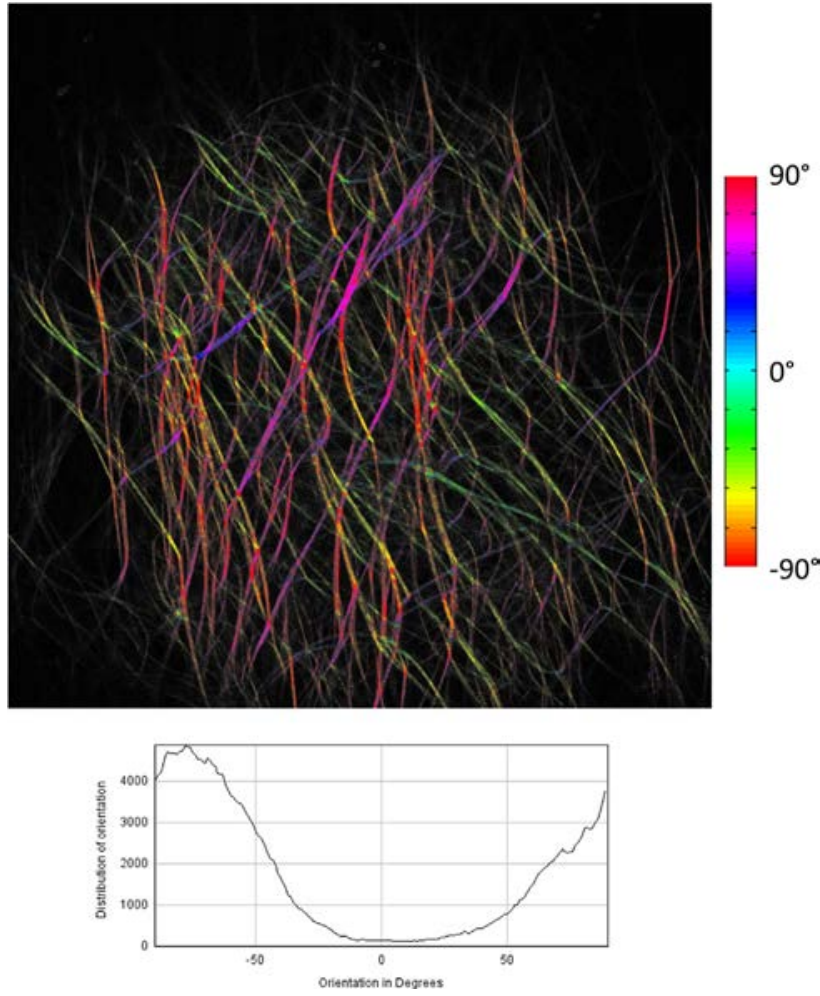

Fig. 5 - Orientations of collagen fibers of the liver capsule measured by the OrientationJ plugin of ImageJ developed by Rezakhaniha et al. (2012).

all test and served as intrinsic markers to compute local strain field at the apex.

\subsection{Strain field computation}

In order to compute local strain field, in plane and out of plane displacements were measured. Via image segmentation through ImageJ, the $\mathrm{XY}$ positions (i.e. the in plane positions) of the photobleached squares centers were collected for each pressure step, from which we derived the $\mathrm{XY}$ displacements of these markers. In order to measure the out of plane displacements (in the $Z$ direction), the altitude variation of a particular plane was assessed along loading. Since photobleaching is not that localized, the photobleaching grid does not appear on only one slice in the stack, but on a group of approximatively 10 of them. Therefore, the planes of appearance and disappearance in the stack of each photobleached square were identified, and a mean plane was calculated. Following the altitude evolution of that mean plane with loading, the vertical displacements ( $\mathrm{Z}$ displacements) of the photobleached squares were calculated. The in plane components of the Green Lagrange strain tensor were then computed from a finite element method interpolation using the fully integrated Belytschko-Tsay membrane elements in the software LS-DYNA $®$.

\subsection{Rupture parameters}

For all the samples, the ultimate values (i.e. the values measured from the last stack taken before rupture) of maximum and mean $E_{\theta \theta}$ and $E_{\varphi \varphi}$, as well as apex vertical position were collected. Ultimate tension $(N)$ at the apex was also calculated according to Flügge (1960) as:

$N=\frac{P R}{2}$,

with $R$ the curvature at the apex, assuming a spherical/ ellipsoidal shape for the samples.

The relative standard deviation (i.e. the ratio between standard deviation and mean value) of these parameters was calculated over the samples for which rupture occurred soon after the last image acquisition. Indeed, in some cases it was difficult to image up to failure, considering that for high pressure values, capsule position stabilization was not achievable. Consequently, only the samples which last image acquisition pressure was $75 \%$ of rupture pressure were considered in that analysis $(n=11)$.

\subsection{Collagen fibers orientation}

The orientation of collagen fibers was calculated based on the images of the SHG channel. Elastin fibers orientations were not calculated as the elastin fibers are arranged in a rather isotropic network wherever the location in the sample.

The plugin of ImageJ OrientationJ was used to compute orientation according to the method described in Rezakhaniha et al. (2012). The orientation calculation relies on the computation of a structure tensor around each pixel of the image. Therefore, a preferred orientation is calculated for each pixel of the image and the associated histogram presents the total pixel number counted in a given direction.

The Gaussian gradient structure tensor was chosen to calculate the distribution of orientation in every slice of each stack. Min coherency and min energy parameters were set to $2 \%$, to filter out the small noise of the images, and a Gaussian window of 1 pixel was chosen. Fig. 5 illustrates this orientation calculation on an image showing collagen fibers and the associated histogram. Results were analyzed in two different ways. First we paid attention to the evolution of orientation along the stack before loading to detail the microstructure organization at a close to 0 stress state. Second, we analyzed the evolution of orientation in the thickness with equibiaxial and non equibiaxial loading.

\section{Results}

\subsection{Liver capsule microstructural arrangement}

Fig. 6 presents an example of the unloaded liver capsule microstructure at different altitudes along the thickness. The collagen fibers, which estimated diameters vary from 2 to $5 \mu \mathrm{m}$, are surrounded by elastin fibers - with smaller diameters of $0.2-0.8 \mu \mathrm{m}$ - that join them in a totally stochastic manner. This all arrangement creates a very complex fiber network.

The observed structure type and organization depend slightly on the chosen location on the liver. However, from a global point of view, wherever the location, this complex chaotic fiber network is always found with approximately the 

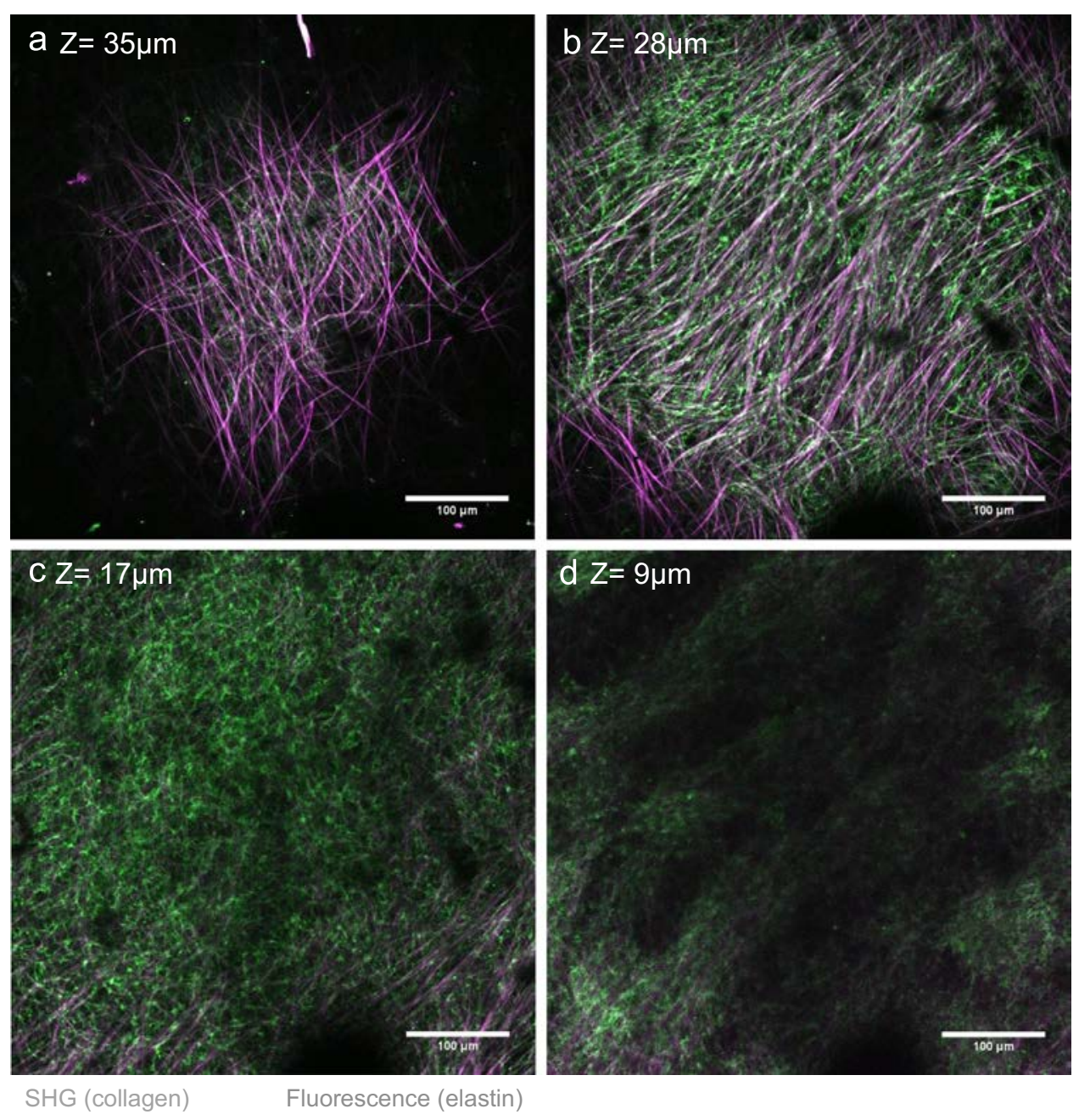

Fig. 6 - Variation of collagen and elastin fibers content along the thickness of human liver capsule observed with multiphoton microscopy. Green corresponds to the fluorescence channel that shows the elastin fibers, while the Second Harmonic Generation (SHG) signal on which appear collagen fibers is shown in magenta. (a) Plane close to the outer surface located at $35 \mu \mathrm{m}$ from the inner surface mainly composed of collagen fibers. (b) Plane located at $28 \mu \mathrm{m}$ from the inner surface with oriented collagen fibers (in magenta) linked by elastin fibers (in green). c) Plane located at $17 \mu \mathrm{m}$ from the inner surface with a high content on fluorescent mater. (d) Plane near the inner surface $(z=9 \mu \mathrm{m})$ composed mainly of collagen fascicles and ECM. (For interpretation of the references to color in this figure legend, the reader is referred to the web version of this article.)

same elastin/collagen content ratio and the same variation along the thickness.

Collagen/elastin ratio is not homogenous in the thickness. Indeed, in the outer region, we can observe more distinct collagen fibers and less elastin fibers that appear as very thin and short fibers that connect collagen fibers (Fig. 6a and b). This particular organization is visible on a $20-40 \mu \mathrm{m}$ thick stack, with a progressive transition towards the organization of the inner region. At the opposite, in the inner region close to the parenchyma, a high concentration of autofluorescent matter is observed that corresponds to the rest of theextracellular matrix (ECM), as well on a $20-40 \mu \mathrm{m}$ thick stack. In this area, collagen fibers can also be found but they assemble in very thick fascicles, densely packed and continuous that prevent from distinguishing individual fibers from one to another (Fig. 6d).

There are very few collagen fibers oriented in the thickness direction. Fascicles and fibers mainly remain in the planes parallel to the one of the liver capsule. Fibers can be tortuous or not, and when they are they still remain in these parallel planes. Thus, this material is built as a stacking of layered fibers that are joined together by the rest of ECM and elastin fibers. These layers often present some anisotropy with a principal fiber direction, which varies with the considered layer. We can usually identify 4 layers. The first one located near the outer surface present loose fibers, often crimped but with a dominant direction (Fig. 7a). The second one located right underneath at $\sim 5-10 \mu \mathrm{m}$ in the thickness direction is usually oriented at $45-90^{\circ}$ from the previous one. In that layer, fibers appear straight, totally uncrimped with a very distinct dominant orientation (Fig. 7b). Then, as we go deep in the tissue, we find a disorganized layer with no clear orientation and less and less distinct fibers as the collagen fibers assembled in fascicles (Fig. 7c). Eventually, the final inner layer closest from the parenchyma presents uncrimped 

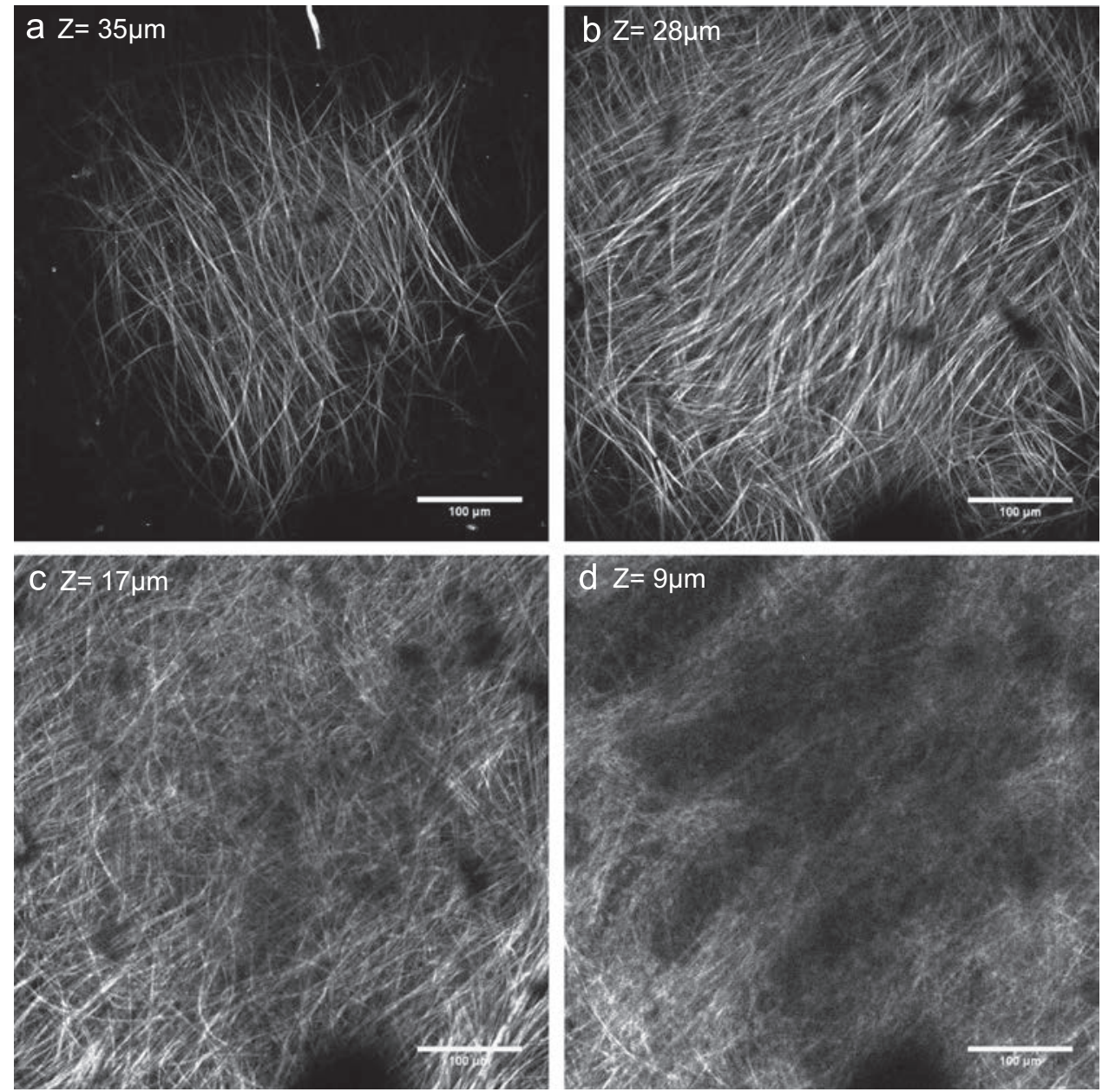

Fig. 7 - Variation along thickness of the organization of human liver capsule collagen fibers as seen on the SHG channel of the two photon excitation microscope. (a) First collagen fibers layer located close to the outer surface at $\mathrm{z}=35 \mu \mathrm{m}$ from the inner surface. (b) Second collagen fibers layer underneath the first layer $(z=28 \mu \mathrm{m}$ from the inner surface) and with a different orientation. (c) Third layer with disorganized collagen fibers at $z=17 \mu \mathrm{m}$ form the inner surface. (d) Layer at the inner surface $(z=9 \mu \mathrm{m})$ presenting collagen fascicles where collagen fibers cannot be distinguished from one to another.

thick fibers/fascicles that are oriented in a dominant direction (Fig. 7d).

The distribution of orientation along thickness is presented on Fig. 8. The two peaks of orientation that correspond to the first two layers are clearly identified. The second layer appears as the one with the most distinct preferred orientation as shown by the greater pixel number oriented in the main direction, compared to the first layer, which was the case for all the samples considered. The marked orientation of the fascicles in the 4th layer near the inner surface is not revealed by this orientation calculation.

\subsection{Local strain fields}

Meridional $\left(E_{\theta \theta}\right)$ and circumferential $\left(E_{\varphi \varphi}\right)$ strains were computed. Fig. 9a b shows an example of the local strain evolution with loading where the nodes of the finite element mesh that correspond to the centers of photobleached squares are indicated. $E_{\theta \theta}$ and $E_{\varphi \varphi}$ fields present some heterogeneity but vary in the same range for all the samples considered whatever the shapes.

Along with loading, the photobleached grid drifts away from its original position that was right in the middle at the apex. Fig. 10 illustrates this point showing the ultimate position of the grid relative to the apex (indicated by a blue cross) on an idealized shape of the inflated capsule. This drifting is progressive with pressure increase. It corresponds in fact to a shift of the apex, which position changes slightly during loading. This shift varies between 0 to approximately $300 \mu \mathrm{m}$ depending on the samples.

\subsection{Microstructural re-arrangement}

Regarding orientation evolution with loading, few cases presented reorientation. For equibiaxial loading, the orientation histogram does not vary much all along mechanical loading. In the case of non equibiaxial loading, i.e. for the elliptic set up, reorientation occurs when the fibers are not already aligned in the direction of maximal strain that corresponds to the minor 


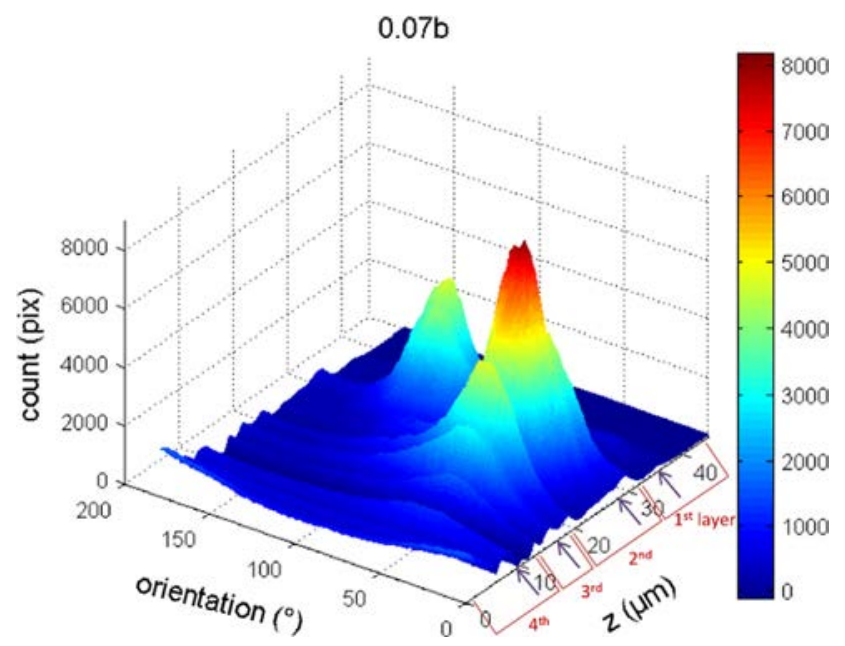

Fig. 8 - Orientation of collagen fibers along thickness before loading $(0.07 \mathrm{bar})$ for one of the circular samples. $Z=0$ corresponds to the inner surface of the sample (near parenchyma) while $z=\mathbf{4 0} \mu \mathrm{m}$ corresponds to the outer surface. The two first oriented layers appear as 2 distinct picks near the outer surface of the sample. The arrows relate to Figs. 6 and 7 and indicate the planes of the images shown.

axis of the ellipses. Fig. 11a and $b$ present the evolution of main fibers direction at different loading steps for a non equibiaxial loading (R2) that showed reorientation. Fig. 11a shows the reorientation of the all thickness of this sample. With pressure increase, the first layer of fibers $(z=30-35 \mu \mathrm{m})$ that was slightly oriented at the beginning, reorients progressively in the principal loading direction to end up with fibers well aligned in that particular direction. The fibers in the second layer are aligned at $\sim 10^{\circ}$ before inflation and progressively lose this particular organization along loading to finally present no distinct orientation at the end of inflation. Fig. 11b highlights this reorganization mechanism showing the orientation histogram of the planes located at $32 \mu \mathrm{m}$ and $20 \mu \mathrm{m}$ from the inner surface at different pressure steps.

\subsection{Rupture analysis}

Table 2 presents the results and especially gives the relative standard deviation (RSD) of all these parameters taken near sample rupture. RSD for apex altitude and $E_{\theta \theta}$ max are within the same range -0.29 and 0.31 respectively-and indicate a rather low variation of these parameters around rupture happening. Pressure and tension RSD are greater -0.47 and 0.48 respectively - showing that force related variables values at rupture have a wider range.

When feasible, the direction of rupture propagation on the sample was collected, to put it in relation with fibers orientation. This rupture orientation was observable 11 times out of the $n=32$ samples tested. For 8 of these cases, rupture propagation occurred in the direction of the fibers of the second layer described previously. 2 of these ruptures were transverse to fibers orientation and the last one was oriented at $45^{\circ}$ from the main fiber direction. Fig. 12 gives an example of these rupture propagation directions put in relation with the main fibers orientations. The location of sample harvesting on liver \#3 is also shown on this schematic view of a liver (illustration from (Netter, 2010)).

\section{Discussion}

The aim of this experimental protocol was to assess the microstructural changes of the liver capsule that occurs when it is subjected to a biaxial loading. The detailed imaging of the microstructure also allowed to give a first description of the particular organization of the liver capsule fibers networks.

\subsection{Microstructure organization}

From a microscopic point of view, liver capsule is composed of elastin fibers and collagen fibers mainly of type I and III (as well as type IV locally) (Chapman and Eagles, 2007; Gelse et al., 2003; Voss et al., 1980). These two fibers network are deeply intertwined and characterize the mechanical behavior of the tissue. Macroscopic experiments have shown that the liver capsule exhibits a nonlinear hyper elastic behavior as many other connective tissues (Brunon et al., 2010; Dan, 1999; Hollenstein and Mazza, 2012). For those collagen/elastin based tissues, the mechanical behavior at small strain comes from the elastin fibers network, whereas the collagen fibers and their recruitment are responsible mainly for the behavior at large strain (Gizzi et al., 2014; Robertson et al., 2012). This hypothesis is reinforced by the different sizes of the fibers that characterize directly their influence on mechanical behavior (Parry, 1988; Roeder et al., 2002). Indeed, the much thinner elastin fibers compared to collagen fibers appears as very straight and short fibers that will be engaged soon during loading and will be responsible for connecting and maintaining the arrangement of collagen fibers, giving to the tissue its elasticity. Collagen fibers present a much stiffer structure because of their bigger diameters and great stiffness (Poissant and Barthelat, 2012). Because of their superior degree of tortuosity compared to elastin fibers, they are involved later in loading until they are recruited and therefore increase the overall stiffness at large strain. 
a
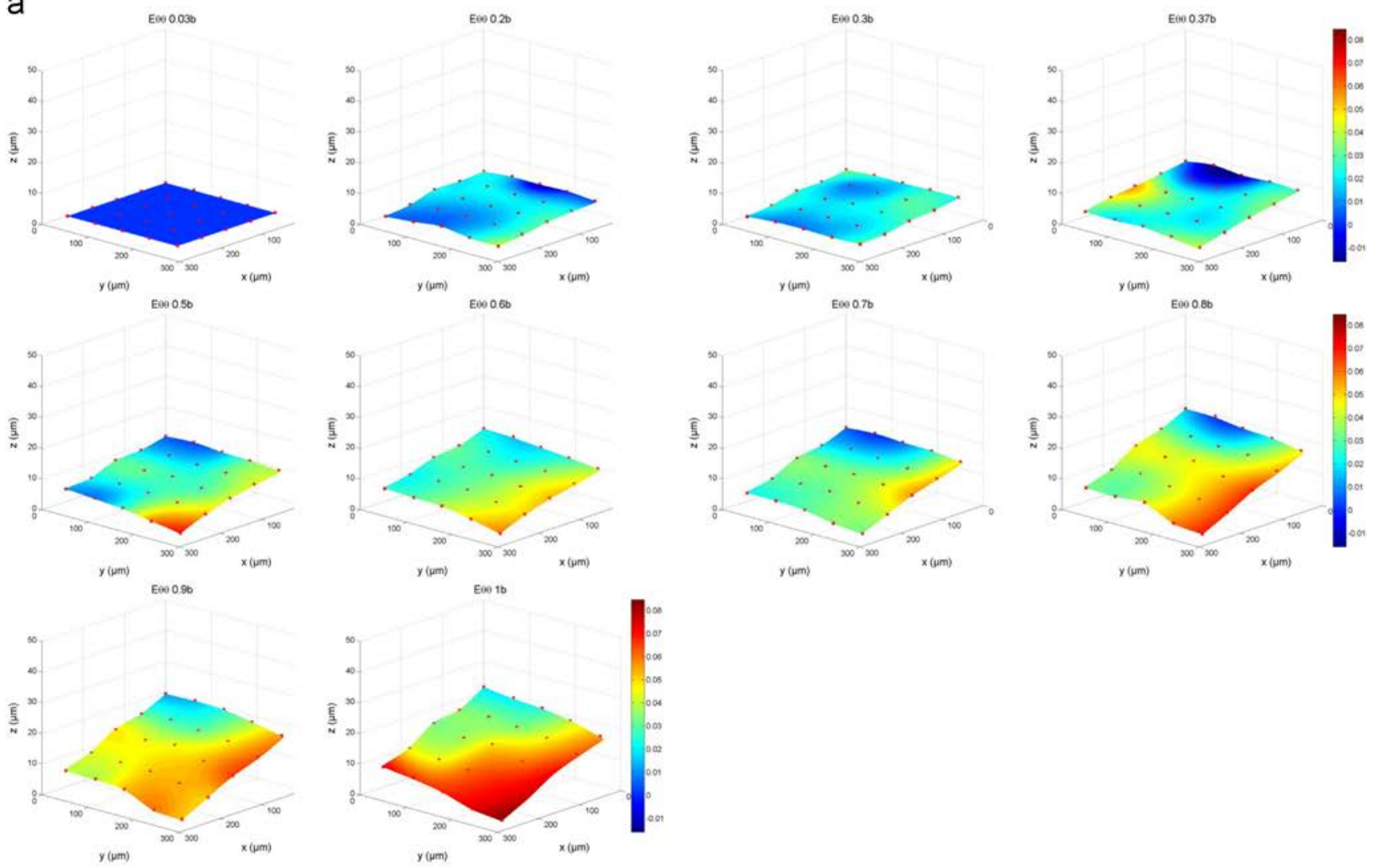

b
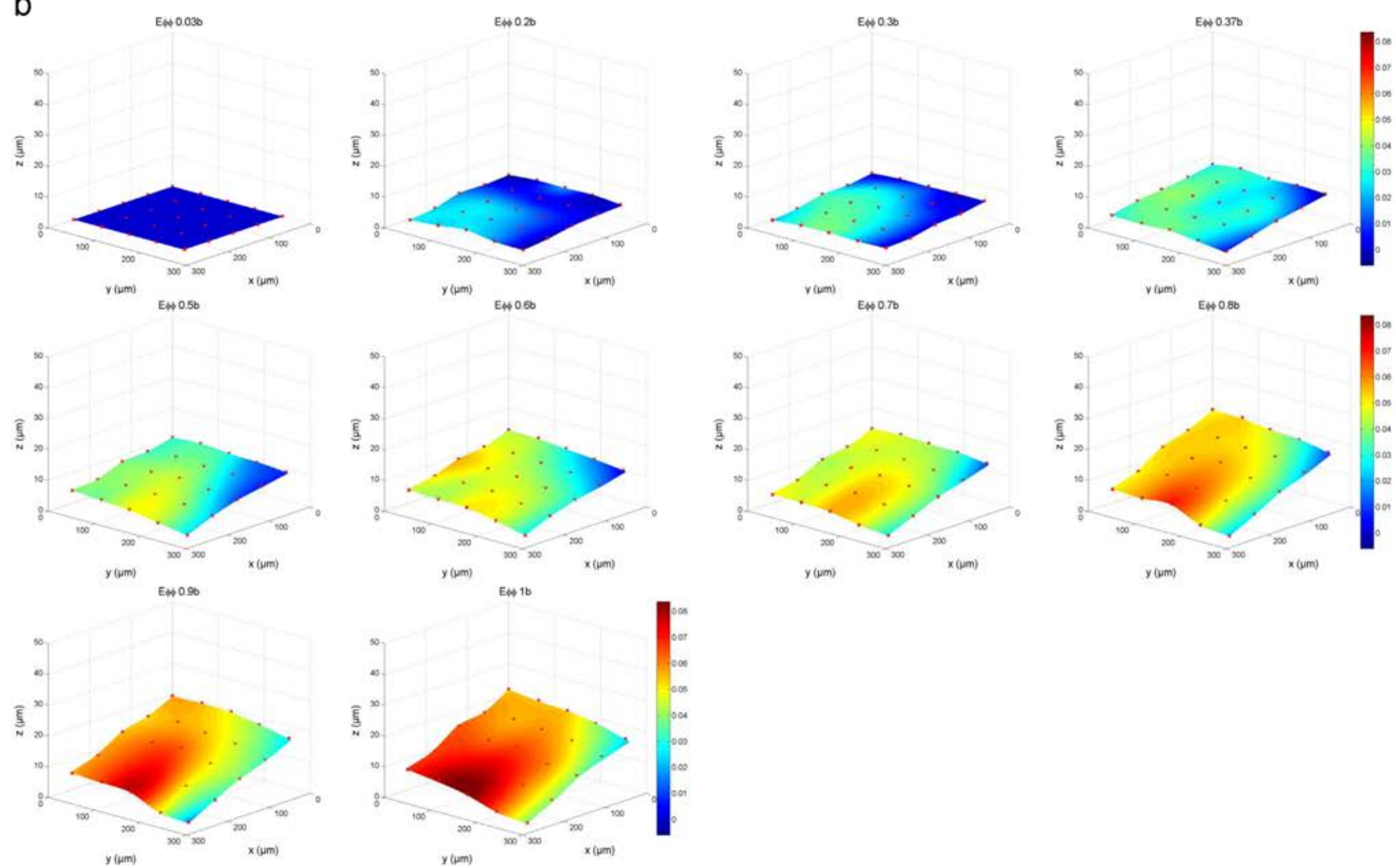

Fig. 9 - Example of Green-Lagrange strain field evolution during loading for an elliptic sample (R4) showing the heterogeneity of local strain in human liver capsule. Each image is associated to a level of pressure measured during image acquisition. The nodes of the finite element mesh that correspond to photobleached squares centers are indicated by red points. a) Meridional strain $\mathbf{E} \theta \theta$ and b) Circumferential strain $\mathbf{E} \varphi \varphi$. (For interpretation of the references to color in this figure legend, the reader is referred to the web version of this article.) 


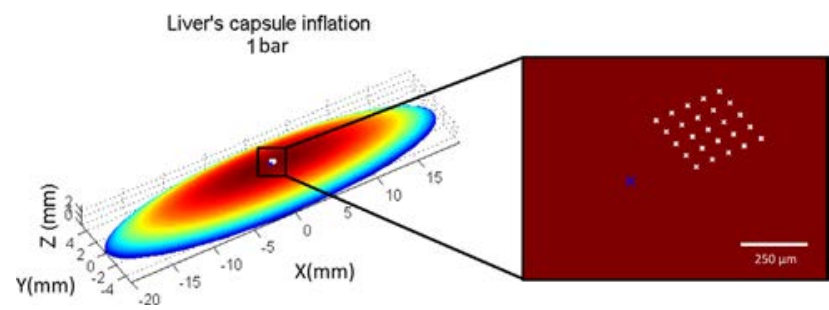

Fig. 10 - Shift of the photobleached grid at the end of loading (1 bar) positioned on an idealized sample shape. The apex of the sample is indicated as a blue cross whereas the white points show the positions of photobleached squares' centers.

a
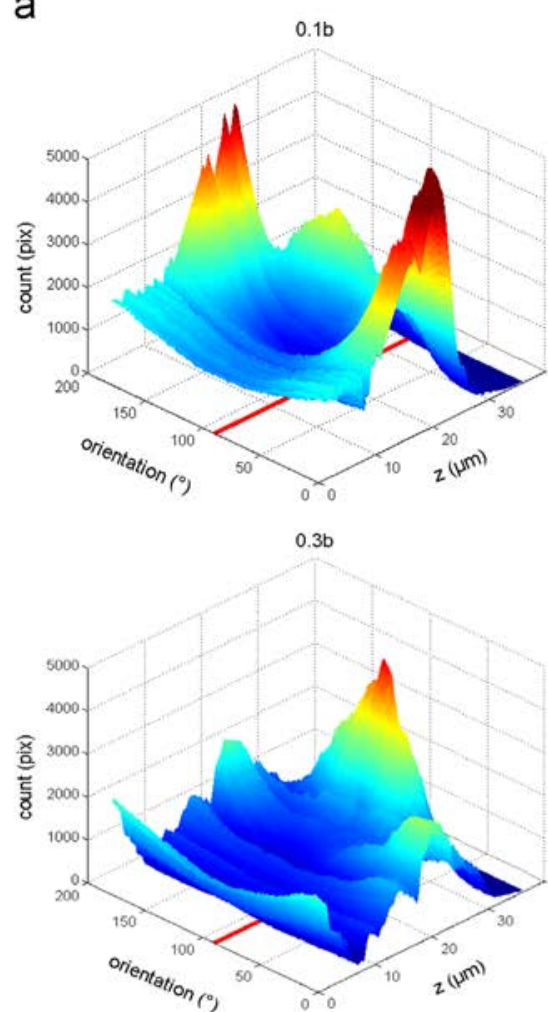

b

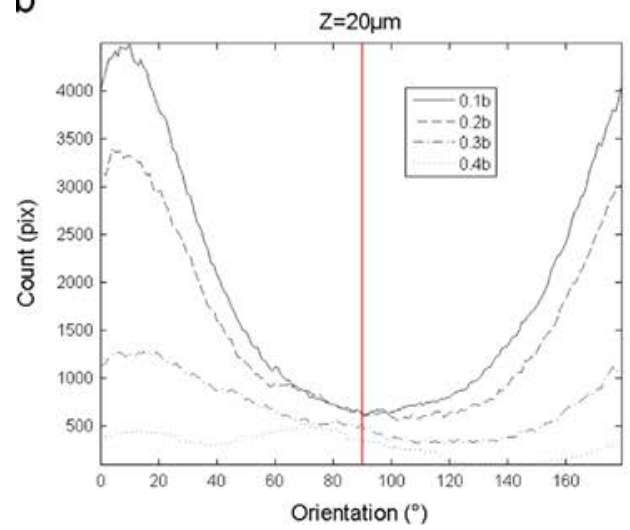

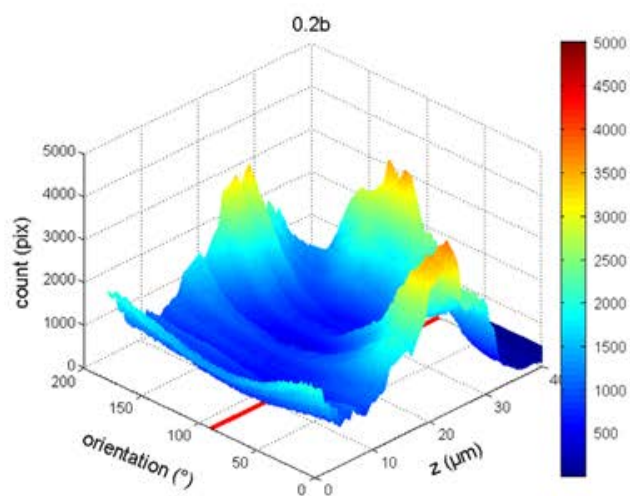
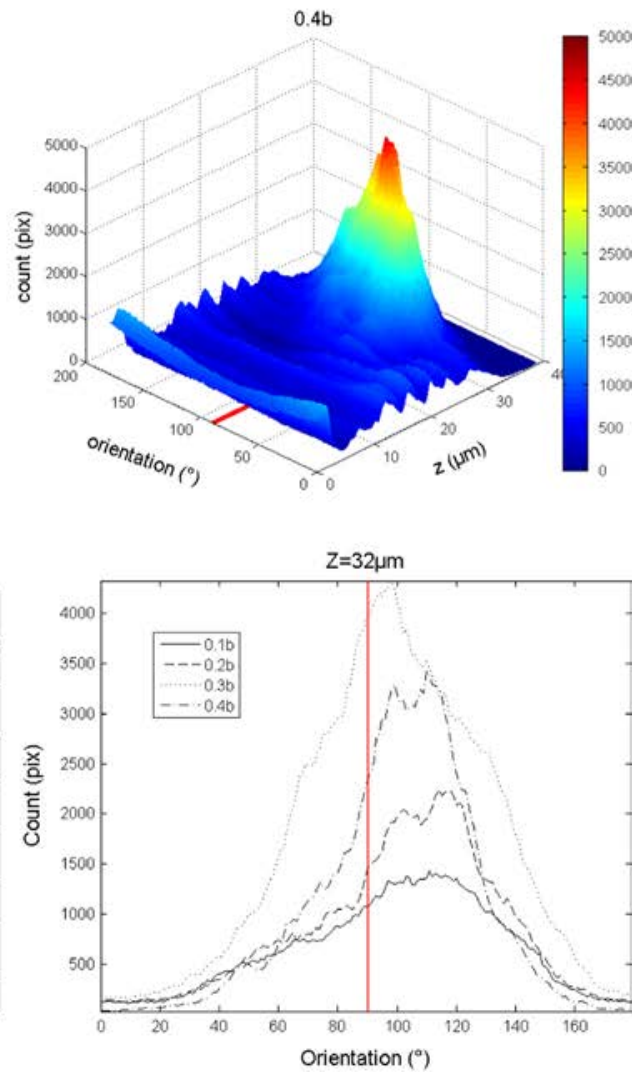

Fig. 11 - Collagen fibers reorientation for a non equibiaxial loading (elliptic sample R2). The minor axis of the sample associated with the principal loading direction has been positioned at $90^{\circ}$. (a) Evolution of collagen fibers orientation in the whole thickness with the increase of pressure. The red line indicates the orientation of the minor axis of the elliptic sample. The fibers gradually aligned with that principal direction. $Z=0$ correspond to the inner surface of the sample (near parenchyma) while $z=\mathbf{4 0} \mu \mathrm{m}$ correspond to the outer surface. (b) Evolution of the collagen fibers layer orientation located in the plane at 20 and $32 \mu \mathrm{m}$ from the inner surface. The red line indicates the direction of the minor axis of the ellipse. (For interpretation of the references to color in this figure legend, the reader is referred to the web version of this article.) 
Table 2 - ' Rupture' parameters for samples which last image pressure level ( $P$ last image) was at least $75 \%$ of rupture pressure. Except for $P$ rupture, all the parameters considered are not truly ultimate values but are calculated from the last image taken before rupture. Relative Standard Deviation (RSD) calculated as ratio between standard deviation and mean value is indicated. Type refers to the shape of the sample (1 is circular, 2 and 4 are elliptic).

\begin{tabular}{|c|c|c|c|c|c|c|c|c|}
\hline \multirow[b]{2}{*}{ Type } & \multicolumn{8}{|c|}{ Rupture para-meters } \\
\hline & $\begin{array}{l}\text { Pressure rupture } \\
\text { (bar) }\end{array}$ & $\begin{array}{l}\text { Pressure at last } \\
\text { image (bar) }\end{array}$ & $\begin{array}{l}\text { Apex altitude } \\
(\mathrm{mm})\end{array}$ & $E_{\theta \theta} \max$ & $E_{\theta \theta}$ mean & $E_{\varphi \varphi} \max$ & $E_{\varphi \varphi}$ mean & $\begin{array}{l}\text { Tension } \\
\left(\mathrm{N} \mathrm{m}^{-1} \times 10^{-2}\right)\end{array}$ \\
\hline R1 & 0.92 & 0.78 & 4.53 & 0.14 & 0.07 & 0.12 & 0.09 & 8.63 \\
\hline R1 & 0.54 & 0.42 & 3.17 & 0.12 & 0.08 & 0.09 & 0.07 & 6.57 \\
\hline R1 & 0.29 & 0.22 & 3.08 & 0.10 & 0.07 & 0.07 & 0.04 & 3.50 \\
\hline R1 & 0.27 & 0.21 & 2.48 & 0.08 & 0.04 & 0.06 & 0.04 & 4.20 \\
\hline R1 & 0.71 & 0.56 & 3.29 & 0.10 & 0.05 & 0.08 & 0.05 & 8.51 \\
\hline R2 & 1.24 & 1.00 & 3.64 & 0.15 & 0.09 & 0.18 & 0.12 & 19.86 \\
\hline R2 & 0.51 & 0.41 & 1.98 & 0.18 & 0.11 & 0.13 & 0.07 & 14.96 \\
\hline R2 & 0.55 & 0.50 & 2.39 & 0.17 & 0.13 & 0.15 & 0.10 & 15.05 \\
\hline R2 & 0.52 & 0.40 & 2.30 & 0.09 & 0.06 & 0.06 & 0.04 & 12.63 \\
\hline R2 & 0.62 & 0.51 & 3.48 & 0.12 & 0.08 & 0.06 & 0.04 & 10.64 \\
\hline $\mathrm{R} 4$ & 0.42 & 0.32 & 1.64 & 0.06 & 0.03 & 0.09 & 0.04 & 9.68 \\
\hline $\begin{array}{l}\text { Relative Standard } \\
\text { Deviation }\end{array}$ & 0.47 & 0.49 & 0.29 & 0.31 & 0.37 & 0.41 & 0.45 & 0.48 \\
\hline
\end{tabular}

The most external layer of collagen fiber in the capsule (Fig. 6a) appears a bit disconnected from the entire coherent network below. Indeed this ensemble of very loose fibers seems to only participate partially to the mechanical response as their recruitment does not arise systematically. This can be explained by the very low concentration of elastin fibers or ECM in that layer, to ensure the connection with the rest of the network. This could also come from friction with other organs that would tend to partially rip off fibers from the underneath layers.

Regarding the slight shift of the apex, it probably comes from the heterogeneity in collagen fibers waviness throughout the all sample. The late recruitment of collagen fibers on a particular side of the sample could lead to a change of apex position in the global unfolding. The various local reorganizations of the fibrous structure to accommodate to loading would cause inevitable adjustments and displacements of the top of the inflated dome. This shift could also come from heterogeneous boundary conditions that could provoke asymmetric slippage of the capsule. Nevertheless it is noteworthy that this phenomenon is of limited amplitude since this displacement is never greater than $300 \mu \mathrm{m}$. The small sizes of our samples probably help in limiting this impact.

\subsection{Microstructural adaptation to loading}

As expected reorientation is not a major phenomenon in the case of equibiaxial loading. Indeed, for the circular shaped samples, fibers main orientation direction do not vary and capsule microstructure organization remains mostly the same all along loading. The only change comes from the aspects of fibers that appear straighter as pressure increases. Initially crimped fibers often progressively unfold but not systematically, meaning that every fibers of the capsule will not necessarily be recruited before rupture. Hill et al. (2012) previously enforced that hypothesis of gradual recruitment by conducting experiment on rabbit carotid arteries and measuring collagen fibers recruitment distribution. For the elliptic samples, reorientation happened systematically to end up with fibers oriented in the minor axis direction. This reorientation was more or less pronounced according to the initial orientation of fibers relatively to the minor axis. Results point out that this reorganization process is gradual and not sudden, and arises all along the pressure increase until failure as shown in Fig. 11.

We noticed that during the reorganization and adaptation to loading, elastin fiber network and collagen fiber network stay strongly linked and united together. Indeed it is the collagen fiber network that seems to dictate the kinematic of reorganization, dragging away with it the elastin network. This would mean that elastin/collagen interactions are stronger than collagen/collagen interactions, since the reorientation mostly takes place among the collagen fibers, modifying their relative arrangement from one another.

\subsection{Rupture mechanism}

The relative low variability for meridional strain near sample rupture tends to indicate that this parameter might be a reliable rupture criterion for modeling purposes. Indeed, as stress is often complicated to assess on such tissues with intertwined fibers networks, using strain to predict rupture instead of force based variables could be a suitable solution. As seen on Table 2, RSD for strain variables are not greater than RSD of force related variables such as pressure or tension, indicating a comparable dispersion and even smaller in our cases, of the values near rupture. However, considering that we had to exclude many of our samples in that analysis when the last image was too far from rupture happening, more tests would be needed to statistically confirm that trend.

The analysis of rupture propagation tends to demonstrate that interactions between collagen fibers are also weaker than the fibers themselves. The bond between collagen fibers seems to be a preferred pathway for rupture propagation and thus, limits the admissible stress to failure 

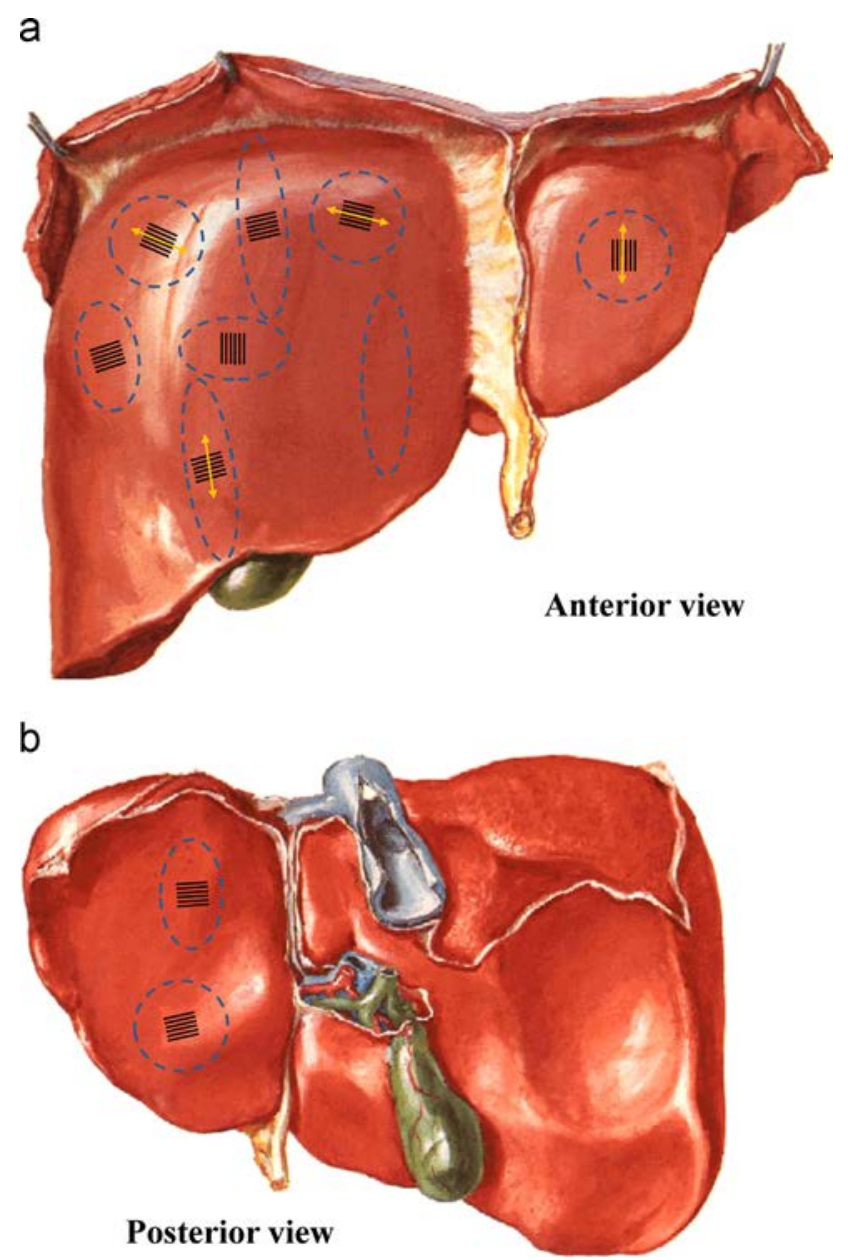

Fig. 12 - Location of sample harvesting for liver \#3 anterior side (a) and posterior side (b), with the different samples shapes. The main orientation of the collagen fibers second layer before loading is indicated in black. Orange arrows correspond to the direction of rupture propagation, when they could be assessed. Illustration adapted from (Netter, 2010). (For interpretation of the references to color in this figure legend, the reader is referred to the web version of this article.)

of the liver capsule. Further tests will be needed to give statistical evidence of this point. The rupture was catastrophic and not gradual at all. This concurs with the failure mechanism identified on fetal membrane involving collagen fibers (Joyce, 2009).

\section{Conclusion}

In this study, a new protocol of in situ bulge testing was developed. Therefore, we were able to use the advantages of bulge testing for the characterization of thin biological membranes, combining them with monitoring of the microstructure evolution. The changes in the collagen and elastin fibers networks were assessed by multiphoton microscopy during a loading that is closer from in vivo conditions than usual uniaxial tensile test. An extensive and detailed description of the liver capsule microstructure was established, giving an insight on natural material design. This particular composition and geometry impact greatly the mechanical behavior via the way the fibers networks react and reorganize to loading. The local strain fields and orientation distribution evolution were calculated to characterize the tissue and relate with local phenomena such as microstructural failure mechanism. This information allows understanding tissue behavior that might influence its functional purpose, and is therefore crucial for tissue engineering application or to develop structurally based models.

\section{Acknowledgments}

The authors thank the IVTV (ANR-10-EQPX-06-01) team and especially Guillaume Fargier for its help during the imaging process.

This work was supported by the Programme Avenir Lyon Saint-Etienne (ANR-11-IDEX-0007) of Université de Lyon, within the Program "Investissements d'Avenir" operated by the French National Research Agency (ANR). 


\section{R E F E R E N C E S}

Brown, I.A., 1973. A scanning electron microscope study of the effects of uniaxial tension on human skin. Br. J. Dermatol. 89, 383-393.

Bruehlmann, S.B., Hulme, P. a, Duncan, Na, 2004. In situ intercellular mechanics of the bovine outer annulus fibrosus subjected to biaxial strains. J. Biomech. 37, 223-231.

Brunon, A., Bruyère-Garnier, K., Coret, M., 2010. Mechanical characterization of liver capsule through uniaxial quasi-static tensile tests until failure. J. Biomech. 43, 2221-2227.

Brunon, A., Bruyère-Garnier, K., Coret, M., 2011. Characterization of the nonlinear behaviour and the failure of human liver capsule through inflation tests. J. Mech. Behav. Biomed. Mater. 4, 1572-1581.

Çakmak, U.D., Kallaí, I., Major, Z., 2014. Temperature dependent bulge test for elastomers. Mech. Res. Commun. 60, 27-32.

Campagnola, P.J., Millard, A.C., Terasaki, M., Hoppe, P.E., Malone, C.J., Mohler, W.A., 2002. Three-dimensional high-resolution second-harmonic generation imaging of endogenous structural proteins in biological tissues. Biophys. J. 82, 493-508.

Chapman, G.B., Eagles, D. a, 2007. Ultrastructural features of Glisson's capsule and the overlying mesothelium in rat, monkey and pike liver. Tissue cell 39, 343-351.

Dan, D., 1999. Caractérisation Mécanique du foie Humain en Situation de choc (Mechanical Characterization of Human Liver in Impact) (Ph.D. thesis). Univ. Paris, Paris7.

Drexler, E.S., Quinn, T.P., Slifka, aJ., McCowan, C.N., Bischoff, J.E., Wright, J.E., Ivy, D.D., Shandas, R., 2007. Comparison of mechanical behavior among the extrapulmonary arteries from rats. J. Biomech. 40, 812-819.

Engler, A.J., Sen, S., Sweeney, H.L., Discher, D.E., 2006. Matrix elasticity directs stem cell lineage specification. Cell 126, 677-689.

Flügge, W., 1960. Stresses in Shells.

Gelse, K., Pöschl, E., Aigner, T., 2003. Collagens-structure, function, and biosynthesis. Adv. Drug Deliv. Rev. 55, 1531-1546.

Gizzi, A., Vasta, M., Pandolfi, A., 2014. Modeling collagen recruitment in hyperelastic bio-material models with statistical distribution of the fiber orientation. Int. J. Eng. Sci. 78, 48-60.

Goulam Houssen, Y., Gusachenko, I., Schanne-Klein, M.-C., Allain, J.-M., 2011. Monitoring micrometer-scale collagen organization in rat-tail tendon upon mechanical strain using second harmonic microscopy. J. Biomech. 44, 2047-2052.

Hildebrandt, J., Fukaya, H., Martin, C.J., 1969. Stress-strain relations of tissue sheets undergoing uniform two-dimensional stretch. J. Appl. Physiol. 27, 758-762.

Hill, M.R., Duan, X., Gibson, G. a, Watkins, S., Robertson, A.M., 2012. A theoretical and non-destructive experimental approach for direct inclusion of measured collagen orientation and recruitment into mechanical models of the artery wall. J. Biomech. 45, 762-771.

Hollenstein, M., Mazza, E., 2012. Mechanical Characterization of the Human Liver. In: Computer Models in Biomechanics: From Nano to Macro.

Jayyosi, C., Fargier, G., Coret, M., Bruyère-Garnier, K., 2014. Photobleaching as a tool to measure the local strain field in fibrous membranes of connective tissues. Acta Biomater. 10, 2591-2601.

Joyce, E.M., 2009. Micromechanical Mechanisms of Fetal Membrane Failure. University of Pittsburgh, Pittsburgh.

Keyes, J. Haskett, D. Utzinger, U., Adaptation of a planar microbiaxial optomechanical device for the tubular biaxial microstructural and macroscopic characterization of small vascular tissues. J., vol. 22, 2011, p. 4109.

Keyes, J.T., Lockwood, D.R., Simon, B.R., Vande Geest, J.P., 2013. Deformationally dependent fluid transport properties of porcine coronary arteries based on location in the coronary vasculature. J. Mech. Behav. Biomed. Mater. 17, 296-306.

Koch, R.G., Tsamis, A., D'Amore, A., Wagner, W.R., Watkins, S.C., Gleason, T.G., Vorp, D. a, 2014. A custom image-based analysis tool for quantifying elastin and collagen micro-architecture in the wall of the human aorta from multi-photon microscopy. J. Biomech. 47, 935-943.

Lake, S.P., Miller, K.S., Elliott, D.M., Soslowsky, L.J., 2010. Tensile properties and fiber alignment of human supraspinatus tendon in the transverse direction demonstrate inhomogeneity, nonlinearity, and regional isotropy. J. Biomech. 43, 727-732.

Liao, J., Yang, L., Grashow, J., Sacks, M.S., 2005. Molecular orientation of collagen in intact planar connective tissues under biaxial stretch. Acta Biomater. 1, 45-54.

Mauri, A., Perrini, M., Mateos, J.M., Maake, C., OchsenbeinKoelble, N., Zimmermann, R., Ehrbar, M., Mazza, E., 2013. Second harmonic generation microscopy of fetal membranes under deformation: Normal and altered morphology. Placenta 34, 1020-1026.

Mauri, A., Perrini, M., Ehret, A.E., De Focatiis, D.S., Mazza, E., 2015. Time-dependent mechanical behavior of human amnion: macroscopic and microscopic characterization. Acta Biomater. 11, 314-323.

Myers, K.M., Coudrillier, B., Boyce, B.L., Nguyen, T.D., 2010. The inflation response of the posterior bovine sclera. Acta Biomater. 6, 4327-4335.

Netter, F.H., 2010. In: E. Saunders (ed.), Atlas of Human Anatomy.

Parry, D. a, 1988. The molecular and fibrillar structure of collagen and its relationship to the mechanical properties of connective tissue. Biophys. Chem. 29, 195-209.

Perrini, M., Bürzle, W., Haller, C., Ochsenbein-Kölble, N., Deprest, J., Zimmermann, R., Mazza, E., Ehrbar, M., 2013. Contractions, a risk for premature rupture of fetal membranes: a new protocol with cyclic biaxial tension. Med. Eng. Phys. 35, 846-851.

Pizzo, a M., Kokini, K., Vaughn, L.C., Waisner, B.Z., Voytik-Harbin, S.L., 2005. Extracellular matrix (ECM) microstructural composition regulates local cell-ECM biomechanics and fundamental fibroblast behavior: a multidimensional perspective. J. Appl. Physiol. 98, 1909-1921.

Poissant, J., Barthelat, F., 2012. In situ mechanical testing of hydrated biological nanofibers using a nanoindenter transducer. Exp. Mech. 52, 1287-1295.

Purslow, P.P., Wess, T.J., Hukins, D.W., 1998. Collagen orientation and molecular spacing during creep and stress-relaxation in soft connective tissues. J. Exp. Biol. 201, 135-142.

Rezakhaniha, R., Agianniotis, a, Schrauwen, J.T.C., Griffa, a, Sage, D., Bouten, C.V.C., van de Vosse, F.N., Unser, M., Stergiopulos, N., 2012. Experimental investigation of collagen waviness and orientation in the arterial adventitia using confocal laser scanning microscopy. Biomech. Model. Mechanobiol. 11, 461-473.

Rivlin, R.S., Saunders, D.W., 1951. Large elastic deformations of isotropic materials. VII. experiments on the deformation of rubber. Philos. Trans. R. Soc. Lond. A: Math. Phys. Eng. Sci. 243, 251-288.

Robertson, A., Hill, M., Li, D., 2012. Structurally motivated damage models for arterial walls. Theory and application. In: Ambrosi, D., Quarteroni, A., Rozza, G. (Eds.), Modeling of Physiological Flows SE-6, MS\&A - Modeling, Simulation and Applications. Springer Milan, Italia, pp. 143-185.

Roeder, B.A., Kokini, K., Sturgis, J.E., Robinson, J.P., Voytik-Harbin, S.L., 2002. Tensile mechanical properties of three-dimensional type I collagen extracellular matrices with varied microstructure. J. Biomech. Eng. 124, 214-222.

Röhrnbauer, B., Ozog, Y., Egger, J., Werbrouck, E., Deprest, J., Mazza, E., 2013. Combined biaxial and uniaxial mechanical 
characterization of prosthetic meshes in a rabbit model. J. Biomech. null.

Sacks, M.S., 2003. Incorporation of experimentally-derived fiber orientation into a structural constitutive model for planar collagenous tissues. J. Biomech. Eng. 125, 280.

Sasaki, N., Odajima, S., 1996. Elongation mechanism of collagen fibrils and force-strain relations of tendon at each level of structural hierarchy. J. Biomech. 29, 1131-1136.

Screen, H.R.C., Evans, S.L., 2009. Measuring strain distributions in tendon using confocal microscopy and finite elements. J. Strain Anal. Eng. Des. 44, 327-335.

Screen, H.R.C., Lee, D.A., Bader, D.L., Shelton, J.C., 2004. An investigation into the effects of the hierarchical structure of tendon fascicles on micromechanical properties. Proc. Inst. Mech. Eng. H 218, 109-119.

Sparks, J.L., 2007. Biomechanics of Blunt Liver Injury: Relating Internal Pressure to Injury Severity and Developing a Constitutive Model of Stress-strain Behavior.

Tonge, T.K., Atlan, L.S., Voo, L.M., Nguyen, T.D., 2013. Full-field bulge test for planar anisotropic tissues: part I-experimental methods applied to human skin tissue. Acta Biomater. 9, 5913-5925.
Tsakalakos, T., Jankowski, A.F., 1986. Mechanical properties of composition-modulated metallic foils. Annu. Rev. Mater. Sci. 16, 293-313.

Valtorta, D., Mazza, E., 2005. Dynamic measurement of soft tissue viscoelastic properties with a torsional resonator device. Med. Image Anal. 9, 481-490.

Voss, B., Rauterberg, J., Allam, S., Pott, G., 1980. Distribution of collagen type I and type III and of two collagenous components of basement membranes in the human liver. Pathol. Res. Pract. 170, 50-60.

Wang, R., Brewster, L.P., Gleason, R.L., 2013. In-situ characterization of the uncrimping process of arterial collagen fibers using two-photon confocal microscopy and digital image correlation. J. Biomech. 46, 2726-2729.

Zoumi, A., Lu, X., Kassab, G.S., Tromberg, B.J., 2004. Imaging coronary artery microstructure using second-harmonic and two-photon fluorescence microscopy. Biophys. J. 87, 2778-2786.

Zoumi, A., Yeh, A., Tromberg, B.J., 2002. Imaging cells and extracellular matrix in vivo by using second-harmonic generation and two-photon excited fluorescence. Proc. Natl. Acad. Sci. USA 99, 11014-11019. 